\title{
Urine Levels of Matrix Metalloproteinases and Tissue Inhibitor of Metalloproteinases in Children with Type 1 Diabetes Mellitus
}

\author{
(D) Zeynep Yürük Yıldırım¹, (D) Alev Yılmaz¹, (D) Cemile Pehlivanoğlu1, (D) Asuman Gedikbaşı², (D) Mehmet Yıldız³, (D) Ahmet Dirican4, \\ (D) Rüveyde Bundak5 , (D) Feyza Darendeliler 5 , (D) Sevinç Emre ${ }^{1}$, (D) Ahmet Nayır ${ }^{1}$ \\ 1 İstanbul University Istanbul Faculty of Medicine, Department of Pediatric Nephrology, Istanbul, Turkey \\ 2Bakırköy Dr. Sadi Konuk Training and Research Hospital, Clinic of Biochemistry, Istanbul, Turkey \\ 3istanbul University istanbul Faculty of Medicine, Department of Pediatrics, Istanbul, Turkey \\ 4 istanbul University istanbul Faculty of Medicine, Department of Biostatistics, Istanbul, Turkey \\ 5istanbul University Istanbul Faculty of Medicine, Department of Pediatric Endocrinology, istanbul, Turkey
}

\begin{abstract}
What is already known on this topic?
It has been demonstrated that mesangial expansion in diabetic nephropathy begins before microalbuminuria occurs. Only a few studies have reported alterations in urine levels of matrix metalloproteinases and tissue inhibitor of metalloproteinases in patients with type 1 diabetes mellitus and these studies have conflicting results.
\end{abstract}

\section{What this study adds?}

The indicators of fibrosis in urine do not increase in the early stage of type 1 diabetes mellitus. This finding suggests that the chronic changes in the kidney evolve at a later stage of the condition.

\section{Abstract}

Objective: Histopathological changes in the kidney in type 1 diabetes mellitus (T1DM) begin before detection of microalbuminuria. Therefore, there is interest in finding a better biomarker for the early detection of diabetic kidney injury. The aim of this present study was to determine whether urinary indicators of fibrosis are detectable early in the development of T1DM in children and if they may predict progressive renal injury.

Methods: Urinary matrix metalloproteinase 2 and 9 (MMP2 and MMP9), tissue inhibitor of metalloproteinase 1 and 2 (TIMP1 and TIMP2) and transforming growth factor- $\beta 1$ (TGF- $\beta 1$ ) were assessed in 33 patients with T1DM with normal renal functions and in 24 healthy controls. Microalbuminuria was not present in the patient group with the exception of three patients. The results were adjusted to urine creatinine $(\mathrm{Cr})$ and the differences between patients and controls were evaluated. These measurements were repeated after one year and the results were compared with the first year results.

Results: Urine MMP2/Cr, MMP9/Cr, TIMP1/Cr, TIMP2/Cr, TGF- $\beta 1 / C r$ were not different between the patient and control groups ( $\mathrm{p}>0.05$ ). There were also no significant differences between the first and second year results for these biomarkers ( $p>0.05$ ). None of these parameters were correlated with hemoglobin A1c, body mass index and duration of T1 DM. Interestingly, all parameters were negatively correlated to age of onset of T1DM $(p<0.05)$

Conclusion: Our findings suggest that urinary biomarkers of fibrosis do not show an increase in diabetic children without microalbuminuria. The results also indicate that the risk of early fibrosis may increase as age of onset of T1DM decreases.

Keywords: Type 1 diabetes mellitus, diabetic nephropathy, children, biomarker, MMP, TIMP

Address for Correspondence: Zeynep Yürük Yıldırım MD, İstanbul University İstanbul Faculty of Medicine, Department of Pediatric Nephrology, İstanbul, Turkey

Phone: + 905323784269 E-mail: znyuruk@gmail.com ORCID ID: orcid.org/0000-0003-2891-2231

'Copyright 2019 by Turkish Pediatric Endocrinology and Diabetes Society

The Journal of Clinical Research in Pediatric Endocrinology published by Galenos Publishing House.
Conflict of interest: None declared Received: 14.09.2018 Accepted: 06.11.2018 


\section{Introduction}

Type 1 diabetes mellitus (T1DM) is one of the most common chronic diseases of childhood $(1,2)$. T1DM causes many macro- and microvascular complications. Diabetic nephropathy (DN) is one of the microvascular complications of T1DM $(3,4)$. If T1DM is not well controlled, it eventually leads to end-stage renal disease (ESRD) due to renal fibrosis $(5,6,7)$. It is known that increased production and decreased degradation of matrix leads to excessive accumulation of extracellular matrix (ECM) components and consequently to development of renal fibrosis (8). Matrix components are regulated by matrix metalloproteinases (MMPs) such as MMP2, MMP9 (9). They cleave denatured collagens, laminin and some cell adhesion molecules and growth factors such as transforming growth factor $\beta$ (TGF- $\beta$ ). Tissue inhibitors of metalloproteinases (TIMPs) are known as regulators of MMPs. TIMPs are usually inhibitory, although sometimes stimulate, MMP activity (10).

The prominent characteristic of DN is ECM accumulation and consequent development of mesangial expansion (8). These changes begin in the second stage of DN and become more prominent in later stages (11). Since MMPs regulate remodeling of ECM, they are important for tissue development (9). MMP2 and MMP9 have a crucial role on the degradation and regulation of ECM in the glomeruli (8). Therefore, MMPs may be involved in the pathophysiology of DN (8). TGF- $\beta 1$ is an important growth factor also involved in kidney fibrosis and DN, via a number of pathways.

It has been suggested that DN usually manifests in adulthood and microalbuminuria is considered as the first laboratory sign of nephropathy (11). Usually, microalbuminuria occurs 6-15 years after diagnosis of T1DM. It would be clinically useful to identify earlier biomarkers than urinary microalbumin for predicting DN thus allowing more effective management and possibly delaying or preventing ESRD.

We hypothesized that the biomarkers of renal fibrosis may increase before microalbuminuria becomes manifest, since microalbuminuria is not the first finding of the disease, but a result of ongoing renal damage in DN (11). The aim of this study was to determine whether urine levels of MMP2, MMP9, TIMP1, TIMP2 and TGF- $\beta 1$ increase in children with $\mathrm{T} 1 \mathrm{DM}$ and serve to predict a progressive renal injury.

\section{Methods}

Thirty-three consecutive patients (18 male, 15 female) with T1DM who attended the outpatient clinic of the Pediatric Endocrinology Department of İstanbul University Faculty of Medicine were enrolled in the study. Demographic and clinical characteristics of the patients are given in Table 1. To our knowledge, there are no standard normative data for urine levels of MMP2, MMP9, TIMP1, TIMP2, TGF- $\beta 1$ in children by age group. For this reason, 24 healthy children (15 male, 9 female) were enrolled in the study as a control group. This study was approved by the İstanbul University of Local Ethics Committee (No: 2013/108) and written informed consent was obtained from the childrens' parents.

A standard physical examination was performed in all patients and blood samples were drawn for biochemical examination. Height and weight measurements of the patients were taken by the same auxologist according to standard methods. Body mass index (BMI) in $\mathrm{kg} / \mathrm{m}^{2}$ was evaluated according to the percentile curves of Turkish children and patients with a BMI above 95th percentile were considered obese (12). Standard deviation (SD) score (SDS) of BMI was calculated according to national data (12). Hypertension was defined as a systolic and/or diastolic blood pressure higher than the 95th percentile for age and gender (13).

Hemoglobin A1c (HbA1c) levels collected within the previous three months were collected from the patient

Table 1. Demographic and clinical characteristics of the patients

\begin{tabular}{ll}
\hline & Mean \pm SD (range) \\
\hline Age (years) & $11.73 \pm 3.82$ \\
& $(4.5-17.8)$ \\
Gender (female/male) & $15 / 18$ \\
& $40.60 \pm 25.5$ \\
DM duration (months) & $(6.4-93.9)$ \\
& $9.11 \pm 2.17$ \\
HbA1c (\%) & $(5.7-15.5)$ \\
& $20.17 \pm 47.51$ \\
Microalbuminuria (mg/g creatinine) & $(1.28-239.41)$ \\
& $19.32 \pm 3.49$ \\
Body mass index & $(13.72-26.65)$ \\
Standard deviation score of body mass & $0.08 \pm 1.01$ \\
index & $(-1.15-2.32)$ \\
Estimated glomerular filtration rate & $157.46 \pm 34.61$ \\
(mL/min/1.73 m²) & $(107.25-303.32)$ \\
& $\mathrm{n}$ \\
Gender (female/male) & $15 / 18$ \\
Pubertal status at first year & $22 / 11$ \\
(pubertal/prepubertal) & \\
The status of metabolic control & \\
- Good (HbA1c 6.5-7.5\%) & 11 \\
- Moderate (HbA1c 7.5-9\% ) Poor (HbA1c > 9\%) & 14 \\
\hline HbA1c: hemoglobin A1c, SD: standard deviation, & DM: diabetes mellitus \\
\hline
\end{tabular}


files. Estimated glomerular filtration rate (GFR) values were calculated by using the Schwartz formula (14). Urinary assessment and urine culture were performed to exclude urinary tract infection for each patient. None of the patients had urinary tract infection. In addition no patient had a record of urinary tract infection, urolithiasis or nephrotoxic drug usage in the past three months. Patients with a urine microalbumin to creatinine (uMA/Cr) ratio greater than $30 \mathrm{mg} / \mathrm{g}$ in at least two of the three urine specimens were considered microalbuminuric (15).

Urine samples were obtained to measure urine levels of MMP2, MMP9, TIMP1, TIMP2, TGF- $\beta$ 1, microalbumin and creatinine. The samples were centrifuged at $4{ }^{\circ} \mathrm{C}$ for 15 minutes at $4,000 \times \mathrm{g}$. Until analyzed, the supernatants were stored at $-80^{\circ} \mathrm{C}$. All processes were performed under uniform conditions in all children. The Abbott Architect C16000 (Illinois, USA) analyzer with original kits was used to measure $\mathrm{uCr}$ and $\mathrm{UMA}$, with uMA expressed in $\mathrm{mg} / \mathrm{L}$ and uMA/Cr expressed in mg/g. Urine levels of MMP2, MMP9, TIMP-1, TIMP-2, TGF- $\beta 1$ were assessed by enzyme-linked immunosorbent assay (ELISA) technique. Urine MMP2, MMP9, TIMP1 and TIMP2 levels were analysed following the manufacturer's instructions, using Human MMP2 ELISA Kit (Cat no: YHB1973Hu), Human MMP9 ELISA Kit (Cat no:YHB1982Hu), Human TIMP-1 ELISA Kit (Cat no: YHB3003Hu), Human TIMP-2 ELISA Kit (Cat no: YHB3004Hu) and Human TGF- $\beta 1$ ELISA Kit (Cat no: YHB3051Hu) purchased from YH Biosearch Laboratory (Pudong District, Shanghail, China). The intra-assay and the inter-assay coefficients of variation for MMP2, MMP9, TIMP1, TIMP2 and TGF- $\beta$ were $<10 \%$ and $<12 \%$, respectively. MMP 2 and TIMP2 levels were expressed as ng/mL, MMP9 and TGF- $\beta 1$ levels as ng/L. TIMP1 levels were expressed as $\mathrm{pg} / \mathrm{mL}$. The results were adjusted per unit of urine/Cr. Results of TGF- $\beta 1 /$ $\mathrm{Cr}$, MMP2/Cr, MMP9/Cr and TIMP2/Cr were expressed as ng/ $\mathrm{mg}$, and TIMP $1 / \mathrm{Cr}$ as $\mathrm{pg} / \mathrm{mg}$. The same measurements were repeated after one year to determine whether urine levels of these markers altered in diabetic children with time.

\section{Statistical Analysis}

Statistical calculations were performed with IBM SPSS Statistics for Windows, Version 22.0. (IBM Inc., Armonk, NY, USA). Besides standard descriptive statistical calculations (mean, standard deviation, median and interquartile range), a t-test was employed in the comparison of two groups and in the assessment of first and second year values. KruskalWallis test was used to compare subgroups of diabetic control and diabetes duration. Pearson correlation test was used in the correlations between variables. Statistical significance level was established at $p<0.05$.

\section{Results}

Mean \pm SD age was $11.73 \pm 3.82$ (range $4.5-17.8$ ) years in the T1DM group and $11.6 \pm 3.0$ years in the controls. There was no statistical difference between the two groups regarding age and gender distribution $(p>0.05)$. Mean \pm SD follow-up duration was $40.6 \pm 25.5$ (range 6.4-93.9) months. All patients were on intensive insulin treatment. Mean \pm SD BMI of the patients was $19.32 \pm 3.49$ (range 13.72-26.65) and mean \pm SD BMI SDS was $0.08 \pm 1.01$ $(-1.15-2.32)$. Normal blood pressure was observed in all patients. Mean \pm SD estimated GFR was $157.46 \pm 34.61$ $\mathrm{mL} / \mathrm{min} / 1.73 \mathrm{~m}^{2}$ (range 107.25-303.32). Mean $\pm \mathrm{SD}$ $\mathrm{HbA1C}$ was $9.11 \pm 2.17 \%$ (range 5.7-15.5). Mean $\pm \mathrm{SD}$ uMA/Cr was $20.17 \pm 47.51$ (range 1.28-239.41) $\mathrm{mg} / \mathrm{g} \mathrm{Cr}$. Urine MMP2/Cr, MMP9/Cr, TIMP1/Cr, TIMP2/Cr, TGF- $\beta 1 /$ $\mathrm{Cr}$ were not different in the patient and control groups ( $p>0.05)$ (Table 2). There was also no significant difference between the results of the first and second year samples of the diabetes patients in these biomarkers $(p>0.05)$. None of these parameters were correlated to age, HbA1c, BMI and duration of T1DM. Interestingly, all parameters were negatively correlated to the age of onset of T1DM $(\mathrm{p}<0.05)$ (Table 3). A positive correlation was found among urine MMP2/Cr, MMP9/Cr, TIMP1/Cr, TIMP2/Cr and TGF- $\beta 1 /$ $\mathrm{Cr}(\mathrm{p}<0.05)$. Microalbuminuria was present in only three patients. Among the three patients with microalbuminuria, only one had higher values of the urine biomarkers than the patients group mean values.

The patients were divided into two subgroups according to duration of diabetes: 0-5 years $(n=19)$ and over 5 years $(n=14)$. There was no difference between the two groups according to urine MMP2/Cr, MMP9/Cr, TIMP1/Cr, TIMP2/ $\mathrm{Cr}$, TGF- $\beta 1 / \mathrm{Cr}$ values (Table 4). Also, the patients were divided into three groups depending on diabetic control as measured by HbA1c: good $(n=8)$, moderate $(n=14)$ and poor glycemic control $(n=11)$ (see Table 5). The urine biomarkers did not differ between the groups with good, moderate or poor glycemic control (Table 5).

\section{Discussion}

Since changes in the ECM are a significant pathogenetic mechanism in DN, we hypothesized that the onset of alterations in urine MMP2, MMP9 and TIMP1, TIMP2 may occur prior to appearance of microalbuminuria. We also expected this change in markers of renal fibrosis to become more prominent with time because kidney injury in DN is a progressive process. However, our results did not support our hypothesis. Urine MMP2/Cr, MMP9/Cr, TIMP1/Cr, TIMP $2 / C r$ values were essentially similar in the patients and controls, 
and they did not change over one year in the T1DM patients. From these results it seems that chronic changes in DN do not begin in the early stages of the disease.

The role of MMPs in the pathogenesis of DN is not fully understood. Although it has been demonstrated that dysregulation of MMPS occurs in DN, the reported results are contradictory (8). Decreased expression of MMP2 and MMP9 was reported in several experimental studies of $\mathrm{DN}$, while other studies reported increased expression of MMPs $(9,16,17)$. Additionally, it has been noted that while MMP2 knock-out mice show an exacerbation of

Table 2. Urinary biomarkers in the patients in the first and second years of onset vs the controls

\begin{tabular}{|c|c|c|c|c|c|c|}
\hline & Control group & $\begin{array}{l}\text { T1DM group first } \\
\text { year }\end{array}$ & $\begin{array}{l}\text { T1DM group second } \\
\text { year }\end{array}$ & \multirow{2}{*}{$\begin{array}{l}\text { Controls vs } \\
\text { T1DM first year } \\
\mathrm{p}\end{array}$} & \multirow{2}{*}{$\begin{array}{l}\text { Controls vs T1DM } \\
\text { second year } \\
\text { p }\end{array}$} & \multirow{2}{*}{$\begin{array}{l}\text { T1DM first vs } \\
\text { second year } \\
\mathrm{p}\end{array}$} \\
\hline & (Mean \pm SD) & $($ Mean \pm SD) & $($ Mean $\pm \mathrm{SD})$ & & & \\
\hline $\begin{array}{l}\mathrm{MMP} 2 / \mathrm{Cr} \\
\mathrm{ng} / \mathrm{mg}\end{array}$ & $0.403 \pm 0.321$ & $0.737 \pm 1.125$ & $0.539 \pm 0.367$ & 0.123 & 0.152 & 0.250 \\
\hline $\begin{array}{l}\mathrm{MMP} 9 / \mathrm{Cr} \\
\mathrm{ng} / \mathrm{mg}\end{array}$ & $1.386 \pm 1.041$ & $2.418 \pm 3.698$ & $1.911 \pm 1.317$ & 0.147 & 0.110 & 0.340 \\
\hline $\begin{array}{l}\text { TIMP1/Cr } \\
\mathrm{pg} / \mathrm{mg}\end{array}$ & $0.286 \pm 0.237$ & $0.478 \pm 0.688$ & $0.359 \pm 0.252$ & 0.182 & 0.276 & 0.245 \\
\hline $\begin{array}{l}\text { TIPMP2/Cr } \\
\mathrm{ng} / \mathrm{mg}\end{array}$ & $0.035 \pm 0.029$ & $0.066 \pm 0.097$ & $0.072 \pm 0.132$ & 0.098 & 0.167 & 0.872 \\
\hline $\begin{array}{l}\text { TGF- } \beta 1 / \mathrm{Cr} \\
\mathrm{ng} / \mathrm{mg}\end{array}$ & $0.795 \pm 0.608$ & $1.145 \pm 1.705$ & $0.893 \pm 0.628$ & 0.324 & 0.561 & 0.309 \\
\hline $\begin{array}{l}\text { MMP2/Cr: ma } \\
\text { TIMP2/Cr: tis } \\
\text { deviation }\end{array}$ & $\begin{array}{l}\text { metalloproteinas } \\
\text { inhibitor of metall }\end{array}$ & $\begin{array}{l}\text { reatinine, MMP9/Cr: } \\
\text { teinase } 2 / \text { creatinine, }\end{array}$ & $\begin{array}{l}\text { x metalloproteinase } 9 / \mathrm{crea} \\
31 / \mathrm{Cr} \text { : transforming growt }\end{array}$ & $\begin{array}{l}\text { ine, TIMP } 1 / \mathrm{Cr} \text { : tiss } \\
\text { actor- } \beta 1 / \text { creatinine, }\end{array}$ & $\begin{array}{l}\text { inhibitor of metallopro } \\
\text { DM: type } 1 \text { diabetes } m\end{array}$ & $\begin{array}{l}\text { inase 1/creatinine, } \\
\text { litus, SD: Standarc }\end{array}$ \\
\hline
\end{tabular}

Table 3. Correlations of urine matrix metalloproteinase/creatinine and tissue inhibitor of metalloproteinases/creatinine with age of onset of the diabetes, with hemoglobin A1c, body mass index and diabetes duration

\begin{tabular}{|c|c|c|c|c|c|}
\hline & & Age of onset of diabetes & $\mathrm{HbA1c}$ & BMI & Diabetes duration \\
\hline \multirow[t]{2}{*}{ MMP2/Cr (ng/mg) } & $\mathrm{r}$ & -0.461 & -0.063 & 0.219 & 0.199 \\
\hline & $\mathrm{p}$ & 0.012 & 0.749 & 0.254 & 0.300 \\
\hline MMP9/Cr (ng/mg) & $\mathrm{p}$ & 0.012 & 0.826 & 0.199 & 0.246 \\
\hline TIMP1/Cr (pg/mg) & $\mathbf{r}$ & -0.484 & -0.076 & 0.214 & 0.205 \\
\hline \multirow[t]{2}{*}{ TIPMP2/Cr (ng/mg) } & $\mathbf{r}$ & -0.422 & -0.070 & 0.262 & 0.211 \\
\hline & $\mathrm{p}$ & 0.023 & 0.724 & 0.170 & 0.272 \\
\hline \multirow[t]{2}{*}{ TGF- $\beta 1 / \mathrm{Cr}$ (ng/mg) } & $\mathbf{r}$ & -0.462 & -0.025 & 0.217 & 0.199 \\
\hline & $\mathrm{p}$ & 0.012 & 0.898 & 0.258 & 0.301 \\
\hline
\end{tabular}

MMP2/Cr: matrix metalloproteinase 2/creatinine; MMP9/Cr: matrix metalloproteinase 9/creatinine, TIMP1/Cr: tissue inhibitor of metalloproteinase 1/creatinine, TIMP $2 / C r$ : tissue inhibitor of metalloproteinase $2 /$ creatinine, TGF- $\beta 1 / \mathrm{Cr}$ : transforming growth factor- $\beta 1 / \mathrm{creatinine}$, HbA1 C: hemoglobin A1 c, BMI: body mass index

Table 4 . The relationships between urine biomarkers and diabetes duration

\begin{tabular}{|c|c|c|c|c|}
\hline & $\begin{array}{l}\text { Control group } \\
(\mathrm{n}=24) \text { (median) }\end{array}$ & $\begin{array}{l}\text { Diabetes duration } 0-5 \text { years } \\
(n=19) \text { (median) }\end{array}$ & $\begin{array}{l}\text { Diabetes duration }>5 \\
\text { years }(n=14) \text { (median) }\end{array}$ & $\mathrm{p}$ \\
\hline MMP2/Cr (ng/mg) & 0.34 & 0.39 & 0.40 & 0.193 \\
\hline MMP9/Cr (ng/mg) & 1.12 & 1.17 & 1.45 & 0.147 \\
\hline TIMP1/Cr (pg/mg) & 0.21 & 0.28 & 0.28 & 0.187 \\
\hline TIMP2/Cr (ng/mg) & 0.03 & 0.04 & 0.03 & 0.120 \\
\hline TGF- $\beta 1 / \mathrm{Cr}$ (ng/mg) & 0.63 & 0.61 & 0.71 & 0.315 \\
\hline
\end{tabular}




\begin{tabular}{|c|c|c|c|c|c|}
\hline & $\begin{array}{l}\text { Control } \\
\text { group }(n=24) \\
\text { (median) }\end{array}$ & $\begin{array}{l}\text { Good glycemic control } \\
\text { HbA1c: } 6.5-7.5 \% \\
(n=8) \text { (median) }\end{array}$ & $\begin{array}{l}\text { Moderate glycemic control } \\
\text { HbA1c: } 7.5-9 \% \\
(\mathrm{n}=14) \text { (median) }\end{array}$ & $\begin{array}{l}\text { Poor glycemic control } \\
\text { HbA1c: }>9 \% \\
(\mathrm{n}=11) \text { (median) }\end{array}$ & $\mathrm{p}$ \\
\hline MMP2/Cr (pg/mg) & 0.34 & 0.52 & 0.43 & 0.35 & 0.319 \\
\hline MMP9/Cr (pg/mg) & 1.12 & 1.53 & 1.43 & 1.33 & 0.531 \\
\hline TIMP1/Cr (pg/mg) & 0.21 & 0.34 & 0.31 & 0.25 & 0.458 \\
\hline TGF- $\beta 1 / \mathrm{Cr}(\mathrm{pg} / \mathrm{mg})$ & 0.63 & 0.75 & 0.65 & 0.62 & 0.934 \\
\hline
\end{tabular}

MMP2/Cr: matrix metalloproteinase 2/creatinine, MMP9/Cr: matrix metalloproteinase 9/creatinine, TIMP1/Cr: tissue inhibitor of metalloproteinase $1 /$ creatinine, TIMP $2 / C r$ : tissue inhibitor of metalloproteinase $2 /$ creatinine, TGF- $\beta 1 / \mathrm{Cr}$ : transforming growth factor $-\beta 1 /$ creatinine, HbA1 c: hemoglobin A1c

DN, MMP9 knock-out mice show an attenuation of DN $(18,19)$. Expression of TIMP1 and TIPM2 are increased in DN $(8,9,20,21)$.

There are only a few studies evaluating urinary MMPs in patients with diabetes. McKittrick et al (22) evaluated urine activities of MMP2 and MMP9 in the urine of patients with T1DM and they found that urinary MMP9 did not differ between the patients and controls; our results are in concordance with these earlier findings. However, unlike our results, they reported an increase in the activities of MMP2 (22). Lauhio et al (23) demonstrated elevation of the urinary activity of MMP9 in adult patients with type 2 DM. However, their study group was quite different from our group. Most of their patients had macroalbuminuria and a diabetes duration longer than 10 years. Tashiro et al (24) evaluated urinary MMP9 in adult patients with type 2 DM who are different our study population. They did not find any differences in urinary MMP9 between normo/ microalbuminuric patients and healthy controls, findings similar to our results. However, in this study, urinary MMP9 were found to be higher in macroalbuminuric patients. van der Zijl et al (25) evaluated urinary MMP2 and MMP9 levels in adult patients with type 2 DM and reported that urinary MMP9 levels were higher in the microalbuminuric group than in the controls, while there was no difference in MMP2 activity. Elevation of urinary MMP9 activity was found to be related to older age, longer duration of diabetes, high levels of HbA1c and increased blood pressure. Thrailkill et al (26) evaluated MMP2 in T1DM patients and found that MMP2 increased in the plasma and urine although they did not find any differences between patients and controls in TIMP1 and TIMP2 concentrations. Similarly to our results, when they evaluated the younger groups ( $<18$ years) they did not find any differences according to urine MMP $2 / \mathrm{Cr}$ and total urine MMP2 concentrations (26). In a later study from the same group Thrailkill et al (27) reported elevation of urinary MMP9 in normoalbuminuric patients with T1DM with duration of diabetes being nine years, a disease duration longer than that of our study group. These studies suggest that the role of the clinical use of urinary MMPs is not fully understood. These differences between the studies may be due to the fact that the patient groups as well as the evaluation method of urine MMPs are quite different from one another. According to these studies, diabetes duration has a significant role on the alteration of urinary MMP2 and MMP9. Also this alteration appears to become more prominent in the later stages of DN. The mean duration of diabetes was only 3.5 years in our patients. ECM accumulation and mesangial expansion begin in the second stage of DN (11). Also, with the exception of three patients, our patients did not have microalbuminuria. We could not demonstrate any differences according to these biomarkers, probably because of the short duration of the diabetic state and because our patients had not yet reached the second and/or later stages of DN. Based on a few previous studies which demonstrated higher values of urine MMP2/Cr and MMP9/Cr in adult diabetic patients, we thought that these markers may increase with time as diabetic injury progresses $(24,25,26,27)$. We also did not find any difference in the values of urinary MMP2/Cr, MMP9/Cr, TIMP/Cr and TIMP2/Cr at initial measurement and when measured a year later. These results show that urine levels of these markers do not change in the early phases of DN and cannot predict early progression of DN.

Some comorbid conditions other than diabetes mellitus such as renal scars, nephrotic syndrome, focal segmental glomerulosclerosis, pancreatic cancer and chronic kidney failure may also affect urine MMP2 and MMP9, TIMP1 and TIMP 2 and TGF- $\beta 1$ concentrations $(28,29,30,31,32,33)$. However, our diabetic patients did not have any known comorbid disorders.

TGF- $\beta 1$ is considered as the most important cytokine in glomerular and tubulointerstitial fibrosis (34). Additionally, expression of TGF- $\beta 1$ is increased with hyperglycemia, thus TGF- $\beta 1$ is involved in various pathways having a role 
in the pathogenesis of DN (34). Furthermore, MMPs not only cleave ECM proteins but also target some non-ECM proteins, including TGF- $\beta 1$, and activation of the TGF- $\beta$ / Smad signal pathway which is accompanied by MMP2 and MMP9 upregulation $(9,10)$. Therefore, in addition to urinary MMPs, we evaluated urinary TGF- $\beta 1$ in our patients. Again TGF- $\beta 1$ was not increased in our patients. In fact, this result was consistent with our results for MMP2 and MMP9. These results suggest that chronic fibrotic changes may not become apparent and these markers do not increase in the urine in the early phases of diabetic kidney injury.

Poor metabolic control, higher BMI, longer duration of disease and onset of diabetes at puberty have been identified as risk factors for DN. Therefore, we evaluated the correlations between these biomarkers and $\mathrm{HbA} 1 \mathrm{c}, \mathrm{BMI}$, duration of T1DM and age of onset of T1DM. Only age of onset was negatively correlated with all these biomarkers of renal fibrosis. This finding suggested that among the indicators of poor prognosis of T1DM in terms of renal damage, the most important determinant seems to be the age of onset of the diabetic state.

\section{Study Limitations}

The limitations of our study are the relatively small sample size with only three microalbuminuric patients. Thus, we were not able to compare microalbuminuric and normoalbuminuric patients for these markers. We did not perform kidney biopsies and thus we are not in a position to make any statements on the pathological DN stage of our patients. Despite these limitations our study has yielded important results. One of the most significant findings was that there were no difference between patients and controls according to these biomarkers and this finding did not change after one year of follow-up. These findings weaken the role of these biomarkers in the detection of early diabetic kidney injury. In this respect, future studies with longer follow-up and larges samples in a pediatric age group are needed to highlight this issue.

\section{Conclusion}

In conclusion, our findings suggest that urinary biomarkers of fibrosis are not increased in diabetic children without microalbuminuria even when disease duration is longer than five years.

\section{Acknowledgement}

We would like to thank our chemist colleague Orhan Tepeli for his support in the handling and storage of the samples.

\section{Ethics}

Ethics Committee Approval: The study was approved by the İstanbul University of Local Ethics Committee (Protocol number: 2013/108).

Informed Consent: Written informed consent was obtained from the childrens' parents.

Peer-review: Externally and internally peer-reviewed.

\section{Authorship Contributions}

Concept: Zeynep Yürük Yıldırım, Alev Yılmaz, Sevinç Emre, Ahmet Nayır, Design: Zeynep Yürük Yıldırım, Alev Yılmaz, Sevinç Emre, Ahmet Nayır, Data Collection or Processing: Zeynep Yürük Yıldırım, Alev Yılmaz, Cemile Pehlivanoğlu, Feyza Darendeliler, Rüveyde Bundak, Asuman Gedikbaşı, Analysis or Interpretation: Zeynep Yürük Yıldırım, Ahmet Nayır, Alev Yılmaz, Cemile Pehlivanoğlu, Mehmet Yıldız, Asuman Gedikbaşı, Feyza Darendeliler, Rüveyde Bundak, Ahmet Dirican, Literature Search: Zeynep Yürük Yıldırım, Alev Yılmaz, Mehmet Yıldız, Writing: Zeynep Yürük Yıldırım, Alev Yılmaz, Mehmet Yıldız, Feyza Darendeliler, Rüveyde Bundak, Ahmet Nayır.

Financial Disclosure: This study was financially supported by the Department of Scientific Research Projects of İstanbul University (Project no: 1850/45064).

\section{References}

1. Newacheck PW, Taylor WR. Childhood chronic illness: prevalence, severity, and impact. Am J Public Health 1992;82:364-371.

2. Karvonen M, Viik-Kajander M, Moltchanova E, Libman I, LaPorte $\mathrm{R}$, Tuomilehto J. Incidence of childhood type 1 diabetes worldwide. Diabetes Mondiale (DiaMond) Project Group. Diabetes Care 2000;23:1516-1526.

3. Wilson JL, Root HF, Marble A. Diabetic nephropathy. A clinical syndrome. N Engl J Med 1951;245:513-517.

4. Andersen AR, Andersen JK, Cbristiansen JS, Deckert T. Prognosis for juvenile diabetics with nephropathy and failing renal function. Acta Med Scand 1978;203:131-134.

5. Dalla VM, Saller A, Bortolosco E, Mauer M, Fioretto P. Structural involvement in type 1 and type 2 diabetic nephropathy. Diab Metabol 2000;26(Suppl 4):8-14.

6. Mauer SM, Steffes MW, Ellis EN, Sutherland DE, Brown DM, Goetz FC. Structural-functional relationships in diabetic nephropathy. J Clin Invest 1984;74:1143-1155.

7. Wolf G. New insights into the pathophysiology of diabetic nephropathy: from haemodynamics to molecular pathology. Eur J Clin Invest 2004;34:785-796.

8. Thrailkill KM, Clay Bunn R, Fowlkes JL. Matrix metalloproteinases: their potential role in the pathogenesis of diabetic nephropathy. Endocrine 2009;35:1-10.

9. Parrish AR. Matrix Metalloproteinases in Kidney Disease: Role in Pathogenesis and Potential as a Therapeutic Target. Prog Mol Biol Transl Sci 2017;148:31-65. Epub 2017 May 4 
10. Cheng Z, Limbu MH, Wang Z, Liu J, Liu L, Zhang X, Chen P, Liu B. MMP2 and 9 in Chronic Kidney Disease. Int J Mol Sci 2017;18:776.

11. Marcovecchio ML, Chiarelli F. Diabetic Nephropathy in Children. In: Avner DE, Harmon EV, Niaudet P, Yoshikawa N, Emma F, Goldstein SL (eds). Pediatric Nephrology. 7th edition. Berlin, Springer-Verlag, 2016;1545-1568.

12. Neyzi O, Bundak R, Gökçay G, Günöz H, Furman A, Darendeliler F, Baș F. Reference Values for Weight, Height, Head Circumference, and Body Mass Index in Turkish Children. J Clin Res Pediatr Endocrinol 2015;7:280-293

13. Flynn JT, Kaelber DC, Baker-Smith CM, Douglas B, Aaron EC, Stephen RD, Sarah DF, Janis MD, Bonita F,Susan KF, Samuel SG, Celeste G, Michael GL, Makia EP, Corinna E, Joshua S, Madeline S, Vidhu VT, Elaine MU. Subcommittee on Screening and Management of High Blood Pressure in Children. Clinical Practice Guideline for Screening and Management of High Blood Pressure in Children and Adolescents. Pediatrics 2017;140:e20171904.

14. Schwartz GJ, Muñoz A, Schneider MF, Mark RH, Kaskel F, Warady BA, Furth SL. New Equations to Estimate GFR in Children with CKD. J Am Soc Nephrol 2008;20:629-637. Epub 2009 Jan 21

15. Alberti KG, Zimmet PZ. Definition, diagnosis and classification of diabetes mellitus and its complications. Part 1: Diagnosis and classification of diabetes mellitus provisional report of a WHO consultation. Diabet Med 1998;15:539-553.

16. Wu K, Setty S, Mauer SM, Killen P, Nagase H, Michael AF, Tsilibary EC. Altered kidney matrix gene expression in early stages of experimental diabetes. Acta Anal (Basel) 1997;158:155-165

17. McLennan SV, Kelly DJ, Cox AJ, Cao Z, Lyons JG, Yue DK, Gilbert RE. Decreased matrix degradation in diabetic nephropathy: effects of ACE inhibition on the expression and activities of matrix metalloproteinases. Diabetologia 2002;45:268-275

18. Takamiya Y, Fukami K, Yamagishi S, Kaida Y, Nakayama Y, Obara N, Iwatani R, Ando R, Koike K, Matsui T, Nishino Y, Ueda S, Cooper ME, Okuda S. Experimental diabetic nephropathy is accelerated in matrix metalloproteinase-2 knockout mice. Nephrol Dial Transplant 2013;28:55-62. Epub 2012 Sep 30

19. Li SY, Huang PH, Yang AH, Tarng DC, Yang WC, Lin CC, Chen JW, Schmid-Schönbein G, Lin SJ. Matrix metalloproteinase-9 deficiency attenuates diabetic nephropathy by modulation of podocyte functions and dedifferentiation. Kidney Int 2014;86:358-369. Epub 2014 Mar 26

20. Han SY, Jee YH, Han KH, Kang YS, Kim HK, Han JY, Kim YS, Cha DR. An imbalance between matrix metalloproteinase-2 and tissue inhibitor of matrix metalloproteinase-2 contributes to the development of early diabetic nephropathy. Nephrol Dial Transplant 2006;21:2406-2416. Epub 2006 May 25

21. Sun SZ, Wang Y, Li Q, Tian YJ, Liu MH, Yu YH. Effects of benazepril on renal function and kidney expression of matrix metalloproteinase-2 and tissue inhibitor of metalloproteinase- 2 in diabetic rats. Chin Med J (Engl) 2006;119:814-821.
22. McKittrick IB, Bogaert $Y$, Nadeau K, Snell-Bergeon J, Hull A, Jiang T, Wang X, Levi M, S. Moulton K. Urinary matrix metalloproteinase activities: biomarkers for plaque angiogenesis and nephropathy in diabetes. Am J Physiol Renal Physiol 2011;301:1326-1333. Epub 2011 Sep 14

23. Lauhio A, Sorsa T, Srinivas R, Stenman M, Tervahartiala T, Stenman UH, Grönhagen-Riska C, Honkanen E. Urinary matrix metalloproteinase $-8,-9,-14$ and their regulators (TRY-1, TRY-2, TATI) in patients with diabetic nephropathy. Ann Med 2008;40:312-320.

24. Tashiro K, Koyanagi I, Ohara I, Ito T, Saitoh A, Horikoshi S, Tomino Y. Levels of urinary matrix metalloproteinase-9 (MMP-9) and renal injuries in patients with type 2 diabetic nephropathy. J Clin Lab Anal 2004;18:206-210.

25. van der Zijl NJ, Hanemaaijer R, Tushuizen ME, Schindhelm RK, Boerop J, Rustemeijer C, Bilo HJ, Verheijen JH, Diamant M. Urinary matrix metalloproteinase- 8 and -9 activities in type 2 diabetic subjects: A marker of incipient diabetic nephropathy? Clin Biochem 2010;43:635639. Epub 2010 Feb 23

26. Thrailkill KM, Bunn RC, Moreau CS, Cockrell GE, Simpson PM, Coleman HN, Frindik JP, Kemp SF, Fowlkes JL. Matrix metalloproteinase-2 dysregulation in type 1 diabetes. Diabetes Care 2007;30:2321-2326. Epub 2007 Jun 11

27. Thrailkill KM, Moreau CS, Cockrell GE, Jo CH, Bunn RC, MoralesPozzo AE, Lumpkin CK, Fowlkes JL. Disease and gender-specific dysregulation of NGAL and MMP-9 in type 1 diabetes mellitus. Endocrine 2010;37:336-343. Epub 2010 Jan 12

28. Chromek M, Tullus K, Hertting O, Jaremko G, Khalil A, Li YH, Brauner A Matrix metalloproteinase- 9 and tissue inhibitor of metalloproteinases- 1 in acute pyelonephritis and renal scarring. Pediatr Res 2003;53:698705. Epub 2003 Feb 20

29. Yilmaz A, Bilge I, Kiyak A, Gedikbasi A, Sucu A, Aksu B, Emre S, Sirin A. Matrix metalloproteinase 9 and tissue inhibitor of metalloproteinase 1 in vesicoureteral reflux. Pediatr Nephrol 2012;27:435-441. Epub 2011 Oct 5

30. Wasilewska AM, Zoch-Zwierz WM. Urinary levels of matrix metalloproteinases and their tissue inhibitors in nephrotic children. Pediatr Nephrol 2008;23:1795-1802. Epub 2008 Jul 2

31. Korzeniecka-Kozerska A, Wasilewska A, Tenderenda E, Sulik A, Cybulski K. Urinary MMP-9/NGAL ratio as a potential marker of FSGS in nephrotic children. Dis Markers 2013;34:357-362.

32. Roy R, Zurakowski D, Wischhusen J, Frauenhoffer C, Hooshmand $\mathrm{S}$, Kulke M, Moses MA. Urinary TIMP-1 and MMP-2 levels detect the presence of pancreatic malignancies. Br J Cancer 2014;111:1772-1779. Epub 2014 Aug 19

33. Musiał K, Bargenda A, Zwolińska D. Urine matrix metalloproteinases and their extracellular inducer EMMPRIN in children with chronic kidney disease. Ren Fail 2015;37:980-984. Epub 2015 May 6

34. Zhang J, Liu J, Qin X. Advances in early biomarkers of diabetic nephropathy. Rev Assoc Med Bras (192) 2018;64:85-92. 